\title{
Augmenting awareness on sustainability of cross-sectoral cooperation
}

\author{
Agnė Slapšinskaitė ${ }^{1}$, Kaija Matinheikki-Kokko², Lukas Galkus ${ }^{3}$, Monika Grincaitė ${ }^{4}$, \\ Justina Vaitkevičiūtè $\dot{5}^{5}$, Asta Raskiliené ${ }^{6}$, Alfonsas Vainoras ${ }^{7}$, Arja Liinamo ${ }^{8}$ \\ $1,3,4,5,6,7$ Health Research Institute, Faculty of Public Health, Medical Academy, Lithuanian University of \\ Health Sciences, Kaunas, Lithuania \\ ${ }^{1}$ Department of Sports Medicine, Faculty of Nursing, Medical Academy, Lithuanian University of Health \\ Sciences, Kaunas, Lithuania \\ ${ }^{2,8}$ Metropolia University of Applied Sciences, Helsinki, Finland \\ ${ }^{1}$ Corresponding author \\ E-mail: ${ }^{1}$ agne.slapsinskaite@lsmuni.lt, ${ }^{2}$ kaija.matinheikki@metropolia.fi, ${ }^{3}$ lukasglk@gmail.com, \\ ${ }^{4}$ monika.grincaite@lsmuni.lt, ${ }^{5}$ justina.vaitkeviciute@lsmuni.lt, ${ }^{6}$ asta.raskiliene@lsmuni.lt, \\ 7alfavain@gmail.com, ${ }^{8}$ arja.liinamo@metropolia.fi
}

Received 26 May 2021; received in revised form 18 June 2021; accepted 29 June 2021 DOI https://doi.org/10.21595/chs.2021.22077

Check for updates

Copyright (C) 2021 Agné Slapšinskaitè, et al. This is an open access article distributed under the Creative Commons Attribution License, which permits unrestricted use, distribution, and reproduction in any medium, provided the original work is properly cited.

\begin{abstract}
It is recognized that health care is an evolving complex adaptive system that requires structural, economic, and organizational resources. Further, its sustainability raises many concerns as sustainability in cooperation of health-promotion is frequently demanded but seldom analysed. Bearing in mind how today's challenges of epidemic, climate changes affect health care systems it evidences the difficulty to plan and predict its positive, smooth evolutionary process. Moreover, the fluctuating, unstable economic status in countries also contributes and augment unpredictability of such system. These instabilities can lead to the disintegration or even collapse of a number of health promotion structures operating in each country. In order to minimize the impact of such events as pandemics, or smoothen cooperation process in general, it is expedient to better understand the possible dynamic stabilizing factors. The first necessity here could be an in-depth case study of cross-sectoral cooperation and self-analysis to organize stabilizing feedback chains to help increase the sustainability of health promotion or health systems in general. In all sense, sustainability research is multidisciplinary; i.e., it addresses the real-life problem such as improved cooperation in health promotion as a way of sustainable financing, which request the complex adaptive systems approach application. Multidisciplinary approach enables people from different disciplines work together, each drawing on their disciplinary knowledge, to create something better.
\end{abstract}

Keywords: health promotion, sustainability, cross-sectoral cooperation, health care system, dynamic evolving system.

\section{Introduction}

\subsection{Sustainability as status quo on health-promotion}

Sustainability in cooperation of health-promotion is frequently demanded but seldom analysed. Herein, we will study sustainability in health-promotion cooperation from the point of view of dynamic decisions in strategic environments. But first of all, we encourage again to ask ourselves what does sustainability mean? Does it hold status quo on health-promotion and resources? Or else, is it the "new normal" as a new sustainability mindset (increased awareness of the planetary challenges and how they intersect with the discipline or profession we choose to focus on) is emerging as it is consequently requested and (re)negotiated among health-promotion intervention in and through the partnerships?

In the last 70 years, the topic of sustainability in business and partnerships has been defined in many different ways. 1 According to a Scopus search using the keyword "sustainability" on 14th 
of December 2020 retrieved nearly 250,000 publications worldwide, which has grown from a single paper published in the year 1970, to nearly 30,000 papers published in 2020 alone. 2 Today sustainability can arguably be called one of humankind's highest aspirations in the 21 st century [1], a part of everyday vocabulary, unlikely in many ways the concept remains elusive [2].

Usually, sustainability is presented in terms of three dimensions: environmental, economic, and social as in the 1992 Rio declaration it is stated that achieving sustainability requires achieving "economic, social, and environmental goals" [2]. Later, Ben-Eli (2018) also suggests that the word has partly become a general idea of a desired continuity [3]. In all sense, sustainability research is multidisciplinary. It addresses the real-life problem (i.e., improved cooperation in health promotion as a way of sustainable financing) which request the complex adaptive systems approach application. In the multidisciplinary approach, people from different disciplines work together, each drawing on their disciplinary knowledge, to create something better [4]. The dynamic sustainability framework: addressing the paradox of sustainment amid ongoing change was also proposed [5]. It developed out of evolving thinking and collective experience in conducting and advancing implementation science, where inattention to constant change limit the ability to which implemented interventions are sustained over time in complex clinical and community settings. Dynamic sustainability should be promoted in cooperation of healthpromotion initiatives. But how the cooperation can become even more sustainable?

Firstly, let's present what happens if we lack sustainable coordination and partnership. It can be a matter of life and death, with negative impact due to non-effective work between the sectors to meet the complex needs of residents [6]. It is important to understand that community health needs require often regular interaction among various sectors [7, 8]. Such act, or instance, of working or acting together for a common purpose, or benefit is described as cooperation [9]. If we wish to reach success in health promotion and the reduction of health inequalities, continuous cooperation among different sectors (NGOs, SMEs, etc.) is requested [10].

\subsection{How do we achieve the most effective and sustainable partnerships?}

Health outcomes of citizens may be improved if we do have a clear mission and vision, collaborative action plans, developing and supporting leadership, collected feedback, ensured technical, financial support, motivated stakeholders, and strong partnership [11]. Of a specific interest herein, is the fact that a partnership is an important and ineluctable path towards sustainable and improved population health [12]. However, both the challenge and advantage is that this partnership can be defined as a system where is no "correct" way to do it. Normally, the main factors for a successful partnership involves the description and knowing our commons goals, mutual understanding, motivation, and knowing what each part can offer, as well as strong leadership, regular and structured communication between collaborators $[6,13]$. Three main factors (leadership, motivation, and communication) are considered as essential components for effective and sustainable partnerships. Those factors are approached in Healthy Boost "Urban Labs for Better Health for All in the Baltic Sea Region", funded by the EU Interreg Baltic Sea Region program that aims to develop the Model for cross-sectoral cooperation [14]. The evidence-based model developed in the Healthy Boost project will guide partners towards systematic cross-sectoral cooperation processes that was additionally challenged of COVID-19 pandemic as it was tested in the cities of the Baltic Sea Region during 2020-21.

How are partnerships suited to the current and future problems of public health? We need to bear in mind that health is more than the health sector by itself. The complexity of different factors influencing community welfare requires cross-sectional action in which multiple sectors share their expertise, experience, capacities, and resources in the effective, efficient, and consistent provision of services to the citizens [15]. A strong partnership can help to improve public health and well-being or help deal with multiple community health issues. In Israel, education, health, and agriculture sectors, local governance units, and health management organizations were involved in promoting a healthy and active lifestyle [16]. In Latvia, collaboration engaged between 
the Ministry of Health, associations representing local, regional governments, and NGOs on pursuance a civil society to participate in maternal and child health policy planning and implementation [15]. In Finland, laws that obligate cross-sectoral/inter-sectoral actions for health and well-being have worked well in mandating sector collaboration. To be effective in cross-sectoral cooperation it is required also long-term vision, commitment and permanent structures facilitating cooperation across sectors (Health in all policies HiAP approach) [15]. Moreover, in Finland the Centre of Expertise for Impact Investing launched operations in January 2020. It is part of the administrative organisation of the Ministry of Economic Affairs and Employment, but additionally serves the entire public sector. The public sector determines the desired outcomes, not the method of service provision, and only pays for verifiably produced outcomes [17]. This approach allows service providers to identify new, effective practices. We outlined some examples that showed the importance of closed partnership to reach sustainable cross-sectoral cooperation. We outlined some examples that showed the importance of closed partnership to reach sustainable cross-sectoral cooperation.

With emergency world-wide of pandemic situations importance of strong and effective partnership has been augmented. A strong collaboration and partnership between the governmental, nongovernmental organizations, scientific community, and private sector helped to manage the Ebola virus disease epidemic in Sierra Leone, or the emerging COVID-19 situation in South Korea and Vietnam [18-20]. As partnership maintenance can be challenging and it may fail $[13,21-23]$ we need to become aware of the main difficulties. For instance, main challenges for partnership are: lack of political will or commitment, a change of government or ministers, limited management capacity, corruption, lack of transparency, struggles with data-sharing, poor communication and conflicts of interests between sectors, competition for resources, and lack of funding $[15,24]$. Collaboration with many parties is important not only for success in health promotion and the reduction of health inequalities, but also a challenging skill that has to be trained to gain more sustainability [25].

\subsection{Are we training how to cooperate?}

Cross-sectoral cooperation is a collaborative effort in which partners from different sectors (public, private, and non-profit) pool their resources to provide joint solutions for common benefit, and address problems and complex challenges. Impact investing is a means of enhancing profitable co-operation between the private, public and third sectors by preventing and solving various well-being and environmental problems. Only approximately a tenth of all social welfare and healthcare funds are channelled toward preventive measures, even though these would be far more economical over the long term than solving problems [22]. Hip fractures and type 2 diabetes are examples of medical conditions that cause significant problems for people and are usually preventable. Impact investing offers a way to make carefully planned, long-term, front-loaded investments. In the current economic situation, central government and local and regional authorities need new tools or learning strategies for promoting and financing well-being [26].

It is well documented that a small change in the payoff environment, which induces a change in the speed of individual learning, can have a large impact on whether mutual cooperation is learned [27]. This in turn encourages to raise some questions about how to model the payoffs in the environment of health-promotion initiatives in which learning is likely to be an important influence on professional competence and the wish to further cooperate. The results of the repeated deterministic conditions suggest that reinforcement learning is sometimes modelled as the algorithm through which people learn to employ more complex cognitive strategies $[28,29]$. Note again that the learning that goes on in strategic, economic environments is not a simple extension of the study of individual learning. What is learned and memorized at the initial stage by the learner who is performing a training in cooperation (or real on-going cooperation) depends on how others are acting and hence on what they are learning. The simulation of the training provides a positive feedback loop between what user learn and what there is to learn. Therefore, it is not 
surprising that the openness to learn can be so important, and that factors that have a small effect on the speed of individual learning can have a large effect on the whole path of real-life sustainable cooperation.

We might focus on community-based participatory research (CBPR) - an approach that combines research methods and community capacity-building strategies to narrow the gap between knowledge produced through research and the application of this knowledge into interventions and policies. The CBPR has received the increased attention of academia and the public health communities to address the persistent problem of disparities in the use of health care and health outcomes, especially among vulnerable populations (i.e., identified by diagnosis, socioeconomic status, lack of health insurance, and membership in various racial and ethnic groups). CBPR attempts to strengthen a community's problem-solving capacity through collective engagement in the research process. The main goals of CBPR are to improve research quality, community capacity, and health outcomes [30]. In 1998 Israel and colleagues introduced nine principles of CBPR: 1) recognizing the community as a unit of identity; 2) building on strengths and resources within the community; 3 ) facilitating a collaborative and equitable partnership in all phases of the research; 4) fostering co-learning and capacity building among all partners; 5) balancing knowledge and action for the mutual benefit of all partners; 6) addressing locally-relevant health problems and considers multiple determinants of health and disease; 7) occurs in a cyclical and iterative process that includes ongoing evaluation of successes and obstacles; 8) disseminating findings and knowledge gained to all partners; 9) involving a long-term process and commitment to sustainability [31,32].

Participatory design (PD) is a research approach to the development of technological solutions to real-world problems, an approach that shares many concerns and some of its roots with action research [33]. In the contemporary era of participation, participatory design research shows how the unique translation and operationalization of participation can be shaped - through critical, political, creative, ethical and empathic approaches - in such a way as to design sustainable technologies and alternative futures in everyday contexts. Participation is often an integrated part of both design research, service and product development. It is applied across research and industry under a diversity of headlines from participatory design, co-design and co-creation to cooperative design and design thinking [34]. For instance, the term "co-design" is used in the scientific literature related to health [35].

Gameful designs (gamification), using design pieces and concepts typically found in the world of games, is a promising approach to increase users' engagement with, and adherence to, electronic health and mobile health (mHealth) tools. However, little is known about the users' requirements and preferences for interactive designs in the context of self-management of chronic conditions. Therefore, patients participating in the co-design process was essential [36]. Co-creation workshops and trainings could be helpful in culturally adapting online mental health systems and increasing accessibility and availability of digital mental health care among vulnerable populations [37]. Another example is medical engineering, where a participatory and co-design process was held via series of stakeholders' workshops, to introduce, to visualize, to mock-up, to prototype, and to package and market a design product [38]. Examining other research field domains, stakeholder participation methodology is quite well established in the field of environmental management, and recommendation was made to avoid a "tool-kit" approach and, instead, emphasized participation or engagement as empowerment, equity, trust, and learning process [39].

\subsection{Why health-promotion should adopt a strategic approach to sustainability goals?}

Sustainable cooperation and generally sustainability within health-promotion might trigger inclusive and participatory processes of stakeholder engagement that could lead to better, more sustainable use of financials at hand. The need to always keep the future in mind when acting today has been a key component in the development of sustainability discourse in the second half 
of the 20th century (1987) [40]. This should be further developed and encouraged in health promotion sector once tackling the sustainability as well in 21 st century as it is highly relevant. For instance, sustainability and corporate social responsibility are positively correlated with economic performance, encouraging organizations to adopt sustainable policies [41]. Once showing a consistent commitment in the dissemination of health-promotion practices and content aimed at creating "shared value" between company and stakeholders - and final user in particular we might better understand why health-promotion should adopt a strategic approach to sustainability goals.

Strategic and operative level approaches are necessary for effective cross-sectoral cooperation. A strategic level approach could be defined as a long-term approach to developing cross-sectoral cooperation. It ensures the success in planning and implementation stages. This approach includes policy change and development, partnership, capacity building, and systemic change [42]. The need for the global and local community to implement integrated and strategic approaches that harness synergies across different sectors and deliver collaborative profit was emphasized in Shanghai Declaration [43].

This approach includes the same mission, vision, goals, objectives, resources, activities, and directions for the actions and management in improving the community's health and well-being. On a strategic level, objectives/actions across multiple sectors should be well coordinated. Also, the cooperation must be supported by local policy leaders, decision-makers, and potential partners (stakeholders/actors outside the municipality, e.g., enterprises NGOs and other public organizations) [44]. Establishing a strategic approach is critical to success, especially living in rapid technology changes. Properly functioning e-Health system can be one of the examples. It enhances access to information, empowerment of patients to make informed healthcare decisions, streamlined organizational processes and transactions, and improved quality, value, and patient satisfaction [45].

An operative level approach could be defined as cross-sectoral cooperative actions and processes that occur in daily practices. This level could be evaluated by assessing how systematically does the organization implement stated cooperative actions. In health promotion, examples of operative approach actions could be that local communities and residents are participating in actions that promote health and well-being, cross-sectoral activities for health and well-being are well-coordinated, and cross-sectoral cooperation process is guided by monitoring and follow-up (e.g., minutes of meetings, verbal discussions, focus groups, observations, interviews, document review, etc.) [44].

The 2030 sustainable development agenda set the scene for innovative approaches to tackling inequities in health [46]. Public authorities are encouraged in local and national health priorities to adapt the agenda and its 17 sustainable development goals (SDGs) [47]. Principles of equality, human rights and sustainable development are added at the core of the agenda. In November 2016, the Ninth Global Conference on Health Promotion highlighted the closely intertwined priorities of the health-promotion and sustainable-development movements, particularly the reduction of the inequity that hampers attempts to achieve several wide developments aims. Integration of multilevel interventions come as one of example of onset approach for health promotion. It outlines the interdependencies, synergies and enablers between the Health 2020 and the 2030 Agenda, thus supporting the proposed roadmap for the WHO European Region [48].

\subsection{The strategic steps of health promotion towards sustainability goals}

Assessment tools and the input of all sectors are needed to establish accountability, increase capacity to address health challenges and to mobilize increased joint resources for implementing cross-sectoral actions [15]. Healthy Boost project addresses the health burden of city residents due to unhealthy lifestyles. Together with 14 partners from seven different countries, it seeks methods and tools to have more capacity for health promotion and to build sustainability through cross-sectoral cooperation with holistic approach to health promotion. The main objective of the 
project is to make urban policies for health and well-being more innovative, effective and integrated. Cross-sectoral cooperation herein is seen as a collaborative effort in which partners from different sectors (public, private, and non-profit) pool their resources to provide joint solutions for common benefit, and address problems and complex challenges. Self-assessment (SA) used and developed in the context of Healthy Boost project offers a tool for evaluating crosssectoral cooperation and helps: a) to assess the current commitment of different stakeholders to cross-sectoral cooperation; b) to highlight strengths and obstacles for active cross-sectoral cooperation; c) to monitor the change by follow up assessment. The striking challenges of our time - such as health care - are complex, whether on a local, national, or international scale. Yet all too often we approach these issues with piecemeal solutions, and with efforts (however passionate, intense, and even exhausting) that aren't sufficient to address the problems at the scale at which they exist. SA-tool demonstrates why individuals or different communities engaged in a cross-sectoral partnership could approach the complexity of working together across sectors in their pursuit of an integrative and sustainable approach and to promote health in the city and municipality (with an emphasis on the operational management). In the future, evidence-based SA-tool and Model for Cross-sectoral Cooperation and training platform (http://www.healthyboost.eu/) produced by Healthy Boost-project will be available guiding cities towards systematic cross-sectoral cooperation for the best of residents' health and well-being.

\section{Conclusions}

In all sense, sustainability research is multidisciplinary; i.e., it addresses the real-life problem such as improved cooperation in health promotion as a way of sustainable financing, which request the complex adaptive systems approach application. Multidisciplinary approach enables people from different disciplines work together, each drawing on their disciplinary knowledge, to create something better. In such case both training (self-learning) and self-assessment might change initial conditions of cooperation. Consequently, it could make process smoother and further lead to more sustainability in the health promotion process. Assessment tools and the input of all sectors are needed to establish accountability, increase capacity to address health challenges and to mobilize increased joint resources for implementing cross-sectoral actions. In the future evidence-based SA-tool, training material and Model for Cross-sectoral Cooperation produced by Healthy Boost-project will be available guiding cities towards systematic cross-sectoral cooperation for the best of residents' health and well-being. Health promotion is a cross-cutting and sustainable development effort that should be prominently integrated into global and local SDGs, such as Agenda 2030, to strengthen cooperation.

\section{Acknowledgements}

We acknowledge Healthy Boost project as the source of support for all activities leading to the preparation of the publication (Healthy Boost Project is co-financed by the European Regional Development Fund through Interreg Baltic Sea Programme).

\section{References}

[1] W. de Vries, J. Kros, C. Kroeze, and S. P. Seitzinger, "Assessing planetary and regional nitrogen boundaries related to food security and adverse environmental impacts," Current Opinion in Environmental Sustainability, Vol. 5, No. 3-4, pp. 392-402, Sep. 2013, https://doi.org/10.1016/j.cosust.2013.07.004

[2] A. A. Zorpas, I. Voukkali, and V. J. Inglezakis, "Business behind sustainability," in Sustainability behind Sustainability, Nova Science Publishers, 2014, pp. 45-71.

[3] M. U. Ben-Eli, "Sustainability: definition and five core principles, a systems perspective," Sustainability Science, Vol. 13, No. 5, pp. 1337-1343, Sep. 2018, https://doi.org/10.1007/s11625-0180564-3 
[4] A. V. Norström et al., "Principles for knowledge co-production in sustainability research," Nature Sustainability, Vol. 3, No. 3, pp. 182-190, Mar. 2020, https://doi.org/10.1038/s41893-019-0448-2

[5] D. A. Chambers, R. E. Glasgow, and K. C. Stange, "The dynamic sustainability framework: addressing the paradox of sustainment amid ongoing change," Implementation Science, Vol. 8, No. 1, pp. 1-11, Dec. 2013, https://doi.org/10.1186/1748-5908-8-117

[6] Shannon Winters, Lilian Magalhaes, Elizabeth Kinsella, and Anita Kothari, "Cross-sector Service Provision in Health and Social Care: An Umbrella Review," International Journal of Integrated Care, Vol. 16, No. 1, pp. 1-19, Apr. 2016, https://doi.org/10.5334/ijic.2460

[7] D. H. Glasby J., Partnership working in health and social care: what Is integrated care and how can we deliver it? 2nd ed. Bristol: Policy Press, 2008.

[8] D. L. Kodner and C. Spreeuwenberg, "Integrated care: meaning, logic, applications, and implications - a discussion paper," International Journal of Integrated Care, Vol. 2, No. 4, pp. 1-6, Nov. 2002, https://doi.org/10.5334/ijic.67

[9] Dictionary, https://www.dictionary.com/browse/cooperation

[10] C. Pollitt, "Joined-up government: a survey," Political Studies Review, Vol. 1, No. 1, pp. 34-49, Jan. 2003, https://doi.org/10.1111/1478-9299.00004

[11] S. T. Roussos and S. B. Fawcett, "A review of collaborative partnerships as a strategy for improving community health," Annual Review of Public Health, Vol. 21, No. 1, pp. 369-402, May 2000, https://doi.org/10.1146/annurev.publhealth.21.1.369

[12] I. Hernandez-Aguado and G. A. Zaragoza, "Support of public-private partnerships in health promotion and conflicts of interest," BMJ Open, Vol. 6, No. 4, p. e009342, Apr. 2016, https://doi.org/10.1136/bmjopen-2015-009342

[13] J. H. Corbin, J. Jones, and M. M. Barry, "What makes intersectoral partnerships for health promotion work? A review of the international literature," Health Promotion International, Vol. 33, No. 1, p. daw061, Aug. 2016, https://doi.org/10.1093/heapro/daw061

[14] A. Slapšinskaitè et al., "Dynamic thinking and complexity: considerations for health promotion," Journal of Complexity in Health Sciences, Vol. 3, No. 1, pp. 104-116, Jun. 2020, https://doi.org/10.21595/chs.2020.21514

[15] "Multisectoral and intersectoral action for improved health and well-being for all: mapping of the WHO European Region. Governance for a sustainable future: improving health and well-being for all." World Health Organization. https://www.euro.who.int/_data/assets/pdf_file/0005/371435/multisectoral-report-h1720-eng.pdf

[16] S. Zach, V. Inglis, A. Zeev, M. Arnon, and Y. Netz, "Active and healthy lifestyle - nationwide programs in Israeli schools," Health Promotion International, Vol. 33, No. 6, pp. 946-957, Dec. 2018, https://doi.org/10.1093/heapro/dax034

[17] "Tasks of the Centre of Expertise for Impact Investing." Ministry of Economic Affairs and Employment (in Finland). https://tem.fi/en/tasks-of-the-centre-of-expertise-for-impact-investing

[18] C. Cancedda et al., "Strengthening health systems while responding to a health crisis: lessons learned by a nongovernmental organization during the Ebola virus disease epidemic in Sierra Leone," Journal of Infectious Diseases, Vol. 214, No. suppl 3, pp. S153-S163, Oct. 2016, https://doi.org/10.1093/infdis/jiw345

[19] J. H. Kim, A.-R. An J., S. J. Jackie Oh, J. Oh, and J. K. Lee, "Emerging COVID-19 success story: South Korea learned the lessons of MERS.". https://ourworldindata.org/covid-exemplar-south-korea

[20] T. Pollack et al., "Emerging COVID-19 success story: Vietnam's commitment to containment.". https://ourworldindata.org/covid-exemplar-vietnam

[21] R. Badinelli, S. Barile, I. Ng, F. Polese, M. Saviano, and P. Di Nauta, "Viable service systems and decision making in service management," Journal of Service Management, Vol. 23, No. 4, pp. 498 526, Aug. 2012, https://doi.org/10.1108/09564231211260396

[22] J. A. Tainter, "Problem solving: complexity, history, sustainability," Population and Environment, Vol. 22, No. 1, pp. 3-41, 2000, https://doi.org/10.1023/a:1006632214612

[23] E.-L. Aveling and S. Jovchelovitch, "Partnerships as knowledge encounters: A psychosocial theory of partnerships for health and community development," Journal of Health Psychology, Vol. 19, No. 1, pp. 34-45, Jan. 2014, https://doi.org/10.1177/1359105313509733

[24] L. Suchman, E. Hart, and D. Montagu, "Public-private partnerships in practice: collaborating to improve health finance policy in Ghana and Kenya," Health Policy and Planning, Vol. 33, No. 7, pp. 777-785, Sep. 2018, https://doi.org/10.1093/heapol/czy053 
[25] "Key Element 6: Collaborate Across Sectors and Levels." Canadian Best Practice Portal. https://cbpppcpe.phac-aspc.gc.ca/population-health-approach-organizing-framework/key-element-6-collaboratesectors-levels/

[26] "Impact investing." The Finnish Innovation Fund Sitra. https://www.sitra.fi/en/topics/impactinvesting/

[27] P. Dal Bó and G. R. Fréchette, "The evolution of cooperation in infinitely repeated games: experimental evidence," American Economic Review, Vol. 101, No. 1, pp. 411-429, Feb. 2011, https://doi.org/10.1257/aer.101.1.411

[28] J. R. Anderson, The adaptive character of thought. New Jersey: Psychology Press, 1990.

[29] I. Erev, G. Barron, "On adaptation, maximization, and reinforcement learning among cognitive strategies," Psychological review, Vol. 112, No. 4, pp. 912-931, 2005, https://doi.org/10.1037/0033295X.112.4.912.

[30] M. Viswanathan et al., "Community-based participatory research: assessing the evidence," Evidence report/technology assessment (Summary), No. 99, Aug. 2004.

[31] B. A. Israel, A. J. Schulz, E. A. Parker, and A. B. Becker, "Review of community-based research: assessing partnership approaches to improve public health," Annual Review of Public Health, Vol. 19, No. 1, pp. 173-202, May 1998, https://doi.org/10.1146/annurev.publhealth.19.1.173

[32] Catherine Riffin et al., "Community-based participatory research: understanding a promising approach to addressing knowledge gaps in palliative care," Annals of Palliative Medicine, Vol. 5, No. 3, pp. 21824-21224, Jun. 2016.

[33] J. Clemensen, S. B. Larsen, M. Kyng, and M. Kirkevold, "Participatory design in health sciences: using cooperative experimental methods in developing health services and computer technology," Qualitative Health Research, Vol. 17, No. 1, pp. 122-130, Jan. 2007, https://doi.org/10.1177/1049732306293664

[34] R. C. Smith, C. Bossen, and A. M. Kanstrup, "Participatory design in an era of participation," CoDesign, Vol. 13, No. 2, pp. 65-69, Apr. 2017, https://doi.org/10.1080/15710882.2017.1310466

[35] J. Langley, D. Wolstenholme, and J. Cooke, "'Collective making' as knowledge mobilisation: the contribution of participatory design in the co-creation of knowledge in healthcare," BMC Health Services Research, Vol. 18, No. 1, pp. 1-10, Dec. 2018, https://doi.org/10.1186/s12913-018-3397-y

[36] S. Jessen, J. Mirkovic, and C. M. Ruland, "Creating Gameful design in mHealth: a participatory codesign approach," JMIR mHealth and uHealth, Vol. 6, No. 12, p. e11579, Dec. 2018, https://doi.org/10.2196/11579

[37] L. Ospina-Pinillos, T. Davenport, A. Mendoza Diaz, A. Navarro-Mancilla, E. M. Scott, and I. B. Hickie, "Using participatory design methodologies to co-design and culturally adapt the spanish version of the mental health eClinic: qualitative study," Journal of Medical Internet Research, Vol. 21, No. 8, p. e14127, Aug. 2019, https://doi.org/10.2196/14127

[38] H. Reed et al., "Head-Up; An interdisciplinary, participatory and co-design process informing the development of a novel head and neck support for people living with progressive neck muscle weakness," Journal of Medical Engineering and Technology, Vol. 39, No. 7, pp. 404-410, Oct. 2015, https://doi.org/10.3109/03091902.2015.1088092

[39] M. S. Reed, "Stakeholder participation for environmental management," Biological Conservation, Vol. 141, No. 10, pp. 2417-2431, Oct. 2008, https://doi.org/10.1016/j.biocon.2008.07.014

[40] G. Bruntland, Our common future. The World Commission on Environment 1 and Development. New York: Oxford University Press, 1987, pp. 45-65.

[41] N. Tomšič, Bojnec, and B. Simčič, "Corporate sustainability and economic performance in small and medium sized enterprises," Journal of Cleaner Production, Vol. 108, pp. 603-612, Dec. 2015, https://doi.org/10.1016/j.jclepro.2015.08.106

[42] "Strategic Approaches." National Center for Healthy Safe Children. https://healthysafechildren.org/strategic-approaches

[43] W. H. Organization, "Shanghai declaration on promoting health in the 2030 Agenda for Sustainable Development," Health Promotion International, Vol. 32, No. 1, pp. 7-8, Feb. 2017, https://doi.org/10.1093/heapro/daw103

[44] M.-K. K. Liinamo A., "Cross-sectoral Cooperation for Health Promotion self-assessed by staff in nine Baltic Sea Region municipalities. Results of municipalities' self-assessment in Healthy," 2020.

[45] K. M. Nazi, "The journey to e-Health: VA healthcare network upstate New York (VISN 2)," Journal of Medical Systems, Vol. 27, No. 1, pp. 35-45, 2003, https://doi.org/10.1023/a:1021005111996 
[46] "Resolution adopted by the General Assembly on 19 September 2016." United Nations, General Assembly, A/RES/71/1, 3 October 2016 (The New York Declaration). https://www.un.org/ga/search/view_doc.asp?symbol=A/RES/70/1\&Lang=E

[47] "Take Action for the Sustainable Development," Goals United Nations Sustainable Development, Available at: https://www.un.org/sustainabledevelopment/sustainable-development-goals/

[48] M. Dyakova et al., "Investment for health and well-being: a review of the social return on investment from public health policies to support implementing the Sustainable Development Goals by building on Health 2020.”. https://www.euro.who.int/_data/assets/pdf_file/0008/345797/hen51.pdf (accessed 2017).

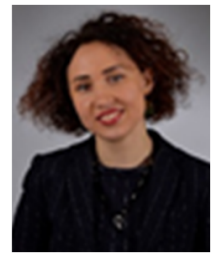

Agnė Slapšinskaitė received a Ph.D. degree in Barcelona University, Barcelona, Spain Physical activity, physical education, and sport (Health and quality of life) in 2017. Currently, she is Lecturer and Researcher at LSMU and is a member of Complex Systems in Sport Research Group, Barcelona. Her research stays took place in the Pontifical Catholic University of Rio Grande do Sul, Porto Alegre, Brazil and Johannes Gutenberg University Mainz, Mainz, Germany. In 2019 she won Chinese Scholarship council grand and made a short post-doc in Beijing Sport University, China. Projects: Psychobiology of exercise; Complexity and metabolic risk; BaltCityPrevention and HealthyBoost (Interreg Baltic Sea Region).

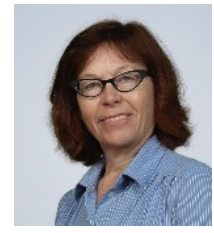

Kaija Matinheikki R\&D Manager at Helsinki Metropolia University of Applied since 2006. Current R\&D focus is on: the well-being of individuals and their functional ability, including well-designed environments throughout the different stages of a person's life; designing multicultural and diverse welfare practices; shared expertise and community based approaches; multidisciplinary rehabilitation competence; customer-oriented products and service innovations.

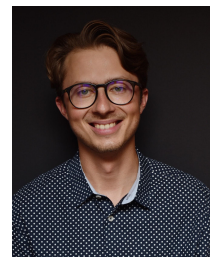

Lukas Galkus is a medical doctor currently working at the Health Research Institute under Lithuanian University of Health Sciences. His professional interests are focused on health topics with special emphasis on psychoactive substances, digital health and healthcare. Currently, Lukas serves as vice-president for youth research at International Youth Health Organization.

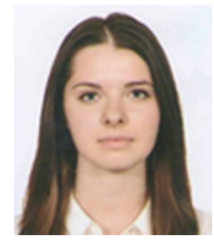

Monika Grincaitė received a Ph.D. degree in Medical and Health Sciences, Public Health from Lithuanian University of Health Sciences, Kaunas, Lithuania, in 2020. Now she works at the Health Research Institute of Faculty of Public Health of Medical Academy, Lithuanian University of Health Sciences. Her current research interests include child and adolescent health, health promotion.

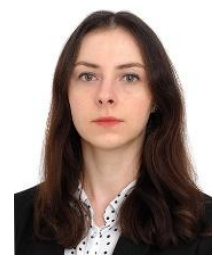

Justina Vaitkevičiūtė received a Ph.D. degree in Medical and Health Sciences, Public Health from Lithuanian University of Health Sciences, Kaunas, Lithuania, in 2020. Now she works at the Health Research Institute, Faculty of Public Health, Medical Academy, Lithuanian University of Health Sciences. In her work, Justina carries out health monitoring studies, participates in various projects, and writes scientific publications. Her current research interests include children growth and tobacco control. 


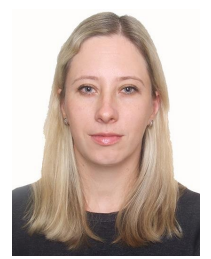

Asta Raskilienè received Ph.D. degree in Biomedical Sciences, Public Health from Lithuanian University of Health Sciences, Kaunas, Lithuania, in 2016. Now she works at Health Research Institute, Faculty of Public Health, Medical Academy, Lithuanian University of Health Sciences. Her current research interests include genetics, health behaviour, and risk of noncommunicable diseases.

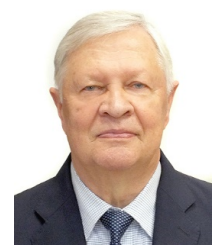

Alfonsas Vainoras received Ph.D. in biomedical sciences, Kaunas Medical Institute in 1980 , dr. habilitatus in 1996, associate professor in 2000, professor in 2003. Now he works at the Health Research Institute of the Faculty of Public Health of Medical Academy, Lithuanian University of Health Sciences. He participates in various projects, and writes scientific publications. His current research interest is development of diagnostic systems in cardiology, complex systems theory application in medicine, public health.

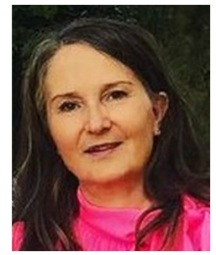

Arja Liinamo first degree was Public Health Nurse in 1983. She received a PhD degree in Health Sciences (Health Education and Promotion) at the University of Jyväskylä, Finland, in 2005. She worked as researcher at the University of Jyväskylä for two years. Since 2006 she has worked as principal lecturer (Health Promotion) at Metropolia University of Applied Sciences, and she is the head of Health Promotion Master's program. She is involved in planning and implementation of several Health and Wellbeing promotion Projects, recently with the focus on Cross-sectoral Health Promotion. 